\title{
Results of a comparative study of low energy direct current with radiofrequency ablation in patients with the Wolff-Parkinson-White syndrome
}

Robert Lemery, Mario Talajic, Denis Roy, Linda Lavoie, Benoit Coutu, John T Y Hii, David Radzik, Eric Lavallee, Richard Cartier

\begin{abstract}
Objective-To compare two new power sources for catheter ablation in patients with the Wolff-Parkinson-White syndrome.

Design-120 consecutive patients with accessory pathways had catheter ablation. Low energy direct current (DC) was used in the first 60 patients and radiofrequency current in the next 60 patients. Setting-Electrophysiological laboratory of a large heart institute.

Patients-72 men and 48 women (mean (SD) age 35 (14) years (range 9-75)). The accessory pathways were in the left free wall in 73 patients. They were posteroseptal in 35 patients, in the right free wall in five, and anteroseptal in seven. There was no significant difference in the clinical or electrophysiological variables between the two ablation groups.
\end{abstract}

Results-Catheter ablation with low energy direct current was successful in $55 / 60$ patients $(92 \%)$ and radiofrequency energy was successful in $52 / 60$ patients $(87 \%)$. Low energy direct current was also successful in four of the eight patients in whom radiofrequency ablation had failed. Radiofrequency ablation was successful in two of the five patients in whom low energy direct current ablation had failed. The mean (SD) procedure and fluoroscopy times for successful ablation were $3.2(1 \cdot 5) \mathrm{h}$ and $61(40) \mathrm{min}$ respectively. These times were similar for both power sources. Accessory pathway conduction recurred in 17 patients (28\%) who had low energy direct current and four patients $(7 \%)$ who received radiofrequency energy $(p<0.004)$. All patients with recurrence of an accessory pathway had successful re-ablation.

Conclusions-Both new power sources successfully ablated accessory pathways, (overall success rate $94 \%(113 / 120$ patients)). Radiofrequency ablation, however, did not require general anaesthesia and was associated with a significantly lower rate of recurrence of accessory pathway conduction. Therefore radiofrequency should be used initially for ablation. Low energy direct current may be most useful as a back-up in patients in whom radiofrequency ablation fails.

(Br Heart $\mathcal{F} 1993 ; 70: 580-584)$

Catheter ablation of accessory pathways was initially reported in $1983 .{ }^{1}$ Using high energy direct current shocks of 150-400 J several workers have since reported success rates of up to $94 \% .^{2-7}$ However, complications are numerous. They include heart block, cardiac tamponade, myocardial infarction, and sudden cardiac death. ${ }^{2-10}$ Most of these complications occur because of significant electrical arcing and barotrauma from both a catheter and a defibrillator that were not designed for catheter ablation. ${ }^{11} 12$

Two new power sources were developed to decrease the risks associated with catheter ablation. The low energy direct current power source (Cardiac Recorders, UK) uses a brief time constant capacitive discharge and delivers shocks of $2-40 \mathrm{~J}$, which eliminate or greatly reduce arcing and barotrauma. ${ }^{13-18}$ The radiofrequency ablation power source (HAT 200 S, Grenzach-Wyhlen, Germany) uses alternating current of $500 \mathrm{kHz}$ in the continuous mode and avoids neuromuscular stimulation and the need for general anesthaesia..$^{19} 20$ Both new systems of energy delivery have been shown to be safe and effective for ablation of accessory pathways. ${ }^{21-24}$ However, both power sources have not been systematically compared, and radiofrequency ablation has occasionally been associated with prolonged procedure and fluoroscopy times, and with variable success rates during the socalled learning phase. ${ }^{25} 26$

We report the results of a comparative study of low energy direct current with radiofrequency ablation of accessory pathways in a consecutive group of patients from a single institution.

\section{Patients and methods}

The study protocol was approved by the Institutional Review Board of the Montreal 
Heart Institute. Written consent was obtained from all patients. In 100 patients (83\%) both the diagnostic electrophysiological study and catheter ablation were performed during the same session. All procedures were done with the patients fasting after antiarrhythmic drugs had been stopped for at least five half-lives.

\section{PATIENTS}

Between May 1989 and January 1992, 120 consecutive patients ( 72 men and 48 women, mean (1 SD) age 35 (14) (range 9-75)) with accessory pathways underwent catheter ablation at the Montreal Heart Institute. There was associated congenital heart disease in four patients (Ebstein's anomaly in three patients and L-transposition of the great vessels in the other). Surgical ablation of a left free wall accessory pathway had previously been unsuccessful in two patients, high energy direct current ablation had failed in three, and in one patient radiofrequency ablation had failed at another institution. Al patients had symptomatic tachycardias with a mean (1 SD) duration of 13 (9) years. Patients had been refractory to a mean (1 SD) of 2 (2) (range 0-6) antiarrhythmic drugs, including amiodarone in nine cases. Orthodromic reciprocating tachycardia was present in 102 patients and atrial fibrillation was present in 18 , leading to cardiovascular collapse in two (associated with malignant syncope (car accident) in one and ventricular fibrillation in the other).

\section{TYPE OF ENERGY DELIVERY}

In the first 60 patients (before April 1991) low energy direct current was used exclusively. Briefly, this new ablator uses an unmodified capacitive discharge to deliver a peak voltage of $2000 \mathrm{~V}$ for shocks of $20 \mathrm{~J}$ over approximately 2-4 ms. ${ }^{1318}$ Unipolar anodal shocks (catheter as the positive pole) were given because they were shown during in vitro studies to increase arcing thresholds. ${ }^{18}$ The indifferent electrode consisted of a large patch positioned under the left scapula. A four channel eight bit digital storage oscilloscope (1604, Gould, Glen Burine, $M D$, USA) was used to record voltage and current over time during each shock.

Radiofrequency ablation was performed in the next 60 patients. The $500 \mathrm{kHz}$ generator was connected to a PC 386 computer with on line measurement and visualisation of the current, duration, impedance, and cumulative energy during each application of radiofrequency. Unipolar ablations were delivered between the tip of the catheter and a patch positioned under the left scapula. When radiofrequency failed the low energy direct current power source was used as a back-up device, and the ablation procedure was then continued. Failure of radiofrequency was defined as the absence of any effect of radiofrequency current on the accessory pathway during procedure times of at least three hours, associated either with endocardial recordings that appeared suitable for ablation or with catheter instability.

\section{CATHETER ABLATION}

A $7 F$ quadripolar deflectable catheter with a $4 \mathrm{~mm}$ distal electrode (Mansfield-Webster catheters, Watertown, MA, USA) was used for all radiofrequency ablations and in the last 21 patients of the low energy direct current group. Early in our experience, a 7F bipolar contoured catheter was used with the low energy power source in 14 patients, while in the remaining patients of this group, a $6 \mathrm{~F}$ quadripolar catheter was used (both catheters from Bard-USCI, Tewkesbury, MA, USA). Therefore, because of the distinct advantage of a deflectable large tip catheter, this electrode was used for ablation in patients 39 to 120.

Table 1 shows the location of the accessory pathway in both groups of patients. Accessory pathways were localised according to previously published criteria. ${ }^{27}$ During mapping the mean cycle length and the mean shortest ventricular-atrial interval during orthodromic reciprocating tachycardia were $336(50)$ and 92 (22) ms respectively for low energy direct current and 339 (51) 86 (21) ms respectively with radiofrequency. There was no significant difference between patients receiving low energy direct current or radiofrequency.

Continuous intravenous heparin (bolus of 2500 units followed by 1000 units/h in adults, bolus of 1000 units followed by 500 units/h in children) was started before ablation. Patients receiving low energy direct current or radiofrequency were anaesthetised with various drugs, including midazolam, fentanyl, nalbufine, thiopentone, propofol, or ketamine. Patients who had radiofrequency ablation did not need general anaesthesia before ablation. The approach for ablation of leftsided accessory pathways consisted of mapping and ablation from a patent foramen ovale (one patient), directly within the coronary sinus (10 patients), and from a retrograde aortic approach to the region of the mitral annulus (63 patients, including 17

Table 1 Accessory pathway location in 120 consecutive patients undergoing catheter ablation

\begin{tabular}{|c|c|c|c|c|c|c|c|c|c|}
\hline \multirow[b]{2}{*}{ Type of accessory pathway } & \multicolumn{3}{|c|}{ Low energy $D C$ (cases $1-60)$} & \multicolumn{3}{|c|}{ Radiofrequency (cases 61-120) } & \multicolumn{3}{|c|}{ All 120 patients } \\
\hline & Manifest & Concealed & Total & Manifest & Concealed & Total & Manifest & Concealed & Total (\%) \\
\hline $\begin{array}{l}\text { Left free wall } \\
\text { Posteroseptal } \\
\text { Right free wall } \\
\text { Anteroseptal } \\
\text { Total }\end{array}$ & $\begin{array}{r}24 \\
13 \\
2 \\
2 \\
41\end{array}$ & $\begin{array}{r}12 \\
5 \\
0 \\
2 \\
19\end{array}$ & $\begin{array}{r}36 \\
18 \\
2 \\
4 \\
60\end{array}$ & $\begin{array}{r}30 \\
12 \\
3 \\
0 \\
45\end{array}$ & $\begin{array}{r}7 \\
5 \\
0 \\
3 \\
15\end{array}$ & $\begin{array}{r}37 \\
17 \\
3 \\
3 \\
60\end{array}$ & $\begin{array}{r}54 \\
25 \\
5 \\
2 \\
86\end{array}$ & $\begin{array}{r}19 \\
10 \\
0 \\
5 \\
34(28 \%)\end{array}$ & $\begin{array}{c}73(61) \\
35(29) \\
5(4) \\
7(6) \\
120\end{array}$ \\
\hline
\end{tabular}

DC, direct current.

All numbers represent patients unless stated otherwise. 
patients who were ablated with radiofrequency current by the single catheter technique). ${ }^{28}$

The low energy direct current power source delivered test shocks of 2-10 J. If they were successful in eliminating conduction through the accessory atrioventricular connection, four to six successive shocks of 15 to $30 \mathrm{~J}$ (aiming for 1500 to $2000 \mathrm{~V}$ per shock) were given to promote tissue damage. When radiofrequency current was used the initial applications consisted of $30 \mathrm{~W}$. This generally was stopped within 20 seconds if accessory pathway conduction was not abolished. After the loss of preexcitation or of retrograde conduction over the accessory pathway, a total of 3-5 applications of 30 seconds of $30-50 \mathrm{~W}$ each of radiofrequency current were delivered. The radiofrequency current was always stopped immediately if impedance increased. In all patients, the maximum duration of a single session was limited to 6-7 hours. Oral anticoagulant was given for three months after low energy direct current ablation. A coated aspirin was given for three months after radiofrequency ablation. All patients have had at least six months of follow up.

\section{STATISTICAL ANALYSES}

All statistical comparisons were performed using an unpaired two-tailed Student's $t$ test. A $p$ value of $<0.05$ was considered significant. Continuous variables are expressed as mean (1 SD).

\begin{abstract}
Results
Table 2 shows the outcome of catheter ablation in all patients. The accessory pathway was successfully ablated in 107 patients (89\%) during the initial ablation session (no significant difference between radiofrequency and low energy direct current ablation). Thirty four patients required additional ablation sessions. In 13 of these the initial ablation procedure had failed. The remaining 21 patients required an additional session because the accessory pathway recurred after an initially successful ablation. There was a significantly greater recurrence of accessory pathway conduction after low energy direct current $(17 / 60$ patients $(28 \%))$ than after radiofrequency energy (4/60 patients $(7 \%)$ ),
\end{abstract}

Table 2 Successful ablation by accessory pathway location in 120 consecutive patients

\begin{tabular}{lll}
\hline Site & Low energy DC (cases 1-60) & Radiofrequency (cases 61-120) \\
\hline Left free wall & $34 / 36$ & $34 / 37$ \\
Posteroseptal & $15 / 18$ & $16 / 17$ \\
Right free wall & $2 / 2$ & $1 / 3$ \\
Anteroseptal & $4 / 4$ & $1 / 3$ \\
All locations & $55 / 60(92 \%)$ & $52 / 60(87 \%)$ \\
& + & + \\
& 4 patients in whom & 2 patients in whom \\
& radiofrequency failed & low energy DC failed $\dagger$ \\
Overall success & & $113 / 120(94 \%)$ \\
\hline
\end{tabular}

DC, direct current.

${ }_{\star}$ Low energy DC was used as a back-up after failure of radiofrequency ablation.

tIn both of these patients (with left free wall accessory pathways) low energy DC ablation tin both of these patients (with left free wall accessory pathways) low energy DC ablation
failed. They returned for another ablation session after March 1991 and radiofrequency ablation was successful in both patients.

All numbers represent patients unless stated otherwise. $(\mathrm{p}<0.004)$. The interval between successful ablation and recurrence of accessory pathway conduction ranged from four hours to three months. Accessory pathway conduction recurred in hospital at three and 24 hours in two patients after radiofrequency ablation and within three weeks after hospital discharge in two other patients. In 17 patients who had low energy direct current ablation accessory pathway conduction, recurred within a week in six patients; between one to four weeks in five patients, and between one to three months in the six others.

The mean procedure time for successful ablation was $3.2(1.2)$ with low energy direct current and $3.1(1.7) \mathrm{h}$ with radiofrequency $(p=N S)$. The mean fluoroscopy times were 57 (30) min with low energy direct current and $66(49) \mathrm{min}$ with radiofrequency $(\mathrm{p}=\mathrm{NS})$.

Fluoroscopy times were significantly related to the site of the accessory pathway. Successful ablation of left free wall accessory pathways required $2 \cdot 7(1 \cdot 3) \mathrm{h}$ of procedure time and 53 (38) $\mathrm{min}$ of fluoroscopy compared with $3.6(1.5) \mathrm{h}$ and $71(40) \mathrm{min}$ for accessory pathways located at other sites ( $p$ $<0.002$ for both procedure and fluoroscopy times). There was no significant difference between procedure or fluoroscopy times in patients with manifest or concealed accessory pathways.

\section{ENERGY DELIVERY}

With low energy direct current the mean number of shocks per session was 10 (5) (range 2-36, median 8) whereas the mean number of radiofrequency applications was 13 (9) (range $3-42$, median 10) $(p<0.005)$. The mean amount of energy was 20 (9) J per shock, corresponding to a cumulative value of 202 (125) J (range 40-650, median 170) when low energy direct current was used. Radiofrequency ablation required 34 (7) W per application for 28 (11) seconds of current delivery. This corresponds to cumulative energies of 13679 (10 356) J (range 1070-60 360, median 10 850). Creatine kinase $\mathrm{MB}$ rose above the normal value (of $0-30$ units $/ 1$ ) in $65 \%$ of patients who had low energy direct current (mean rise of 22 (25) units/l) and in $28 \%$ of patients who had radiofrequency ablation (mean rise of 7 (9) units $/ 1)(p<0.04)$.

\section{COMPLICATIONS AND FOLLOW UP}

There were six complications (during our socalled learning phase of catheter ablation) with low energy direct current. Cardiac tamponade requiring a pericardial window occurred in one patient ${ }^{24}$ and transient pericarditis was seen in three patients. The other two complications were iliac arterial dissection in one patient and microemboli in both feet in a patient treated with coumadin.

Later, when we were using radiofrequency current, there was only one complication. Pneumothorax developed after central venous puncture and the patient required thoracic drainage for $\mathbf{4 8}$ hours but recovered uneventfully.

Intermittent palpitation during follow up 
occurred in $41 \%$ of patients who had low energy direct current ablation and $40 \%$ of patients who had radiofrequency, but none of these patients described symptoms that resembled the episodes of reciprocating tachycardia that they had before ablation. Late electrophysiological studies confirmed the absence of an accessory pathway in 48 $(96 \%)$ of 50 patients who underwent low energy direct current ablation, and accessory pathway conduction was modified in two patients who were symptom free during 12 months of follow up. The late electrophysiological study was normal in 21 (91\%) of 23 patients who received radiofrequency current. Two of these patients had a concealed accessory pathway with reciprocating tachycardia induced during programmed electrical stimulation; radiofrequency ablation was successful in both patients. The remaining patients, who are awaiting a control electrophysiological study, have not had recurrence of paroxysmal supraventricular tachycardia during follow up. Ventricular tachycardia was not inducible (by two ventricular extrastimuli while the right ventricular apex was paced at $400 \mathrm{~ms}$ ) in any of the patients who had a late electrophysiological study.

\section{Discussion}

Both new power sources were successful at ablating accessory pathways. The procedure time and fluoroscopy times varied according to accessory pathway location. ${ }^{2329}$ Left free wall accessory pathways were ablated with very short sessions with either power source. Kuck et al successfully used radiofrequency ablation with the single catheter technique approach for manifest left free wall accessory pathways in 30 of 34 patients. ${ }^{28}$ We too were successful with this technique in all 17 ablations attempted. The mean procedure and fluoroscopy times were $1.8(1 \cdot 1) \mathrm{h}$ and 34 (23) $\mathrm{min}$, respectively. With both power sources accessory pathways in other locations require longer procedure times.

In the eight patients in whom radiofrequency ablation failed we used low energy direct current as a back-up and successfully ablated pathways in four of these patients (left free wall accessory pathway in two patients, posteroseptal in one patient, and anteroseptal in one patient). This suggests that low energy direct current is more likely than radiofrequency ablation to be associated with a favourable outcome in a select subgroup of patients, in whom catheter positioning and stability are very difficult or in whom accessory pathways are presumably located more epicardially than endocardially. ${ }^{30-33}$ Also low energy direct current has been shown to be safe in patients who require ablation within the cornary sinus. ${ }^{17434}$ None the less radiofrequency ablation was achieved within the os of the coronary sinus without complications in three of our patients and Haissaguerre et al showed that radiofrequency current may be given within the coronary sinus. ${ }^{35}$

\section{RECURRENCE OF ACCESSORY PATHWAY}

In our study low energy direct current was associated with significantly more recurrences of accessory pathway conduction than radiofrequency ablation. Shocks delivered at sites remote from the accessory pathway can temporarily cause conduction block, without necessarily creating sufficient necrosis for permanent interruption of the accessory pathway. Unlike the application of low energy direct current, catheter positioning for the application of radiofrequency energy is critical, and ablation is successful only when the energy is delivered directly over the accessory pathway, which may explain the low recurrence rate in these patients. ${ }^{21-23}$

\section{COMPLICATIONS}

Both new power sources seem safe. ${ }^{21-2436}$ There were only six complications (5\%). Other studies of radiofrequency ablation have also reported a low incidence of non-cardiac and cardiac complications-so far cardiac tamponade, ${ }^{21}$ myocardial infarction ${ }^{22}$ and aortic leaflet perforation ${ }^{37}$ have been reported. We found that creatine kinase MB concentration rose above normal values significantly more often and were significantly higher after low energy direct current than after radiofrequency ablation. Although this suggests that low energy direct current is associated with greater amounts of necrosis, Haines et al have recently shown that increases in creatine kinase $M B$ may be underestimated after radiofrequency ablation..$^{38}$ Nonetheless, earlier pathological studies showed that low energy direct current ablation causes larger myocardial lesions than radiofrequency ablation. ${ }^{1739}$

\section{LIMITATIONS OF THE STUDY}

We performed catheter ablation of accessory pathways in 120 consecutive patients over a three year period. Comparison between both groups of patients is limited by two principal factors. The patients who received radiofrequency current benefited from the early experience we acquired using low energy direct current. Also, a deflectable tip was not available in over half of the patients $(39 / 60)$ who received low energy direct current. However, a recent prospective comparison study of catheter ablation of the atrioventricular junction in patients with atrial tachyarrhythmias showed that radiofrequency ablation was safer and more effective than high energy DC ablation. ${ }^{40}$

Radiofrequency current should be used initially in patients with accessory pathways who undergo ablation. Radiofrequency ablation does not require general anaesthesia and is highly successful for ablation of accessory pathways. Furthermore, the precise catheter positioning required for radiofrequency ablation is associated with a significantly lower recurrence of accessory pathway conduction than low energy direct current. The low energy DC power source may be most useful in patients in whom radiofrequency has failed. In some patients it is difficult to apply 
radiofrequency energy for 30 seconds or more because of catheter instability. This can be overcome by giving low energy direct current shocks that are given over only a few milliseconds. Other patients with accessory pathways that are located away from the subendocardium or within the coronary sinus vein may also benefit more from low energy direct current ablation.

We thank the nurses of the clinical electrophysiology laboratory and the members of the Department of Anaesthesia of the Montreal Heart Institute for assistance, the referring physicians for their continuing support, and Ms Christiane Lussier for typing the manuscript.

This study was supported by grants from the Fonds de Recherche en Santé du Québec (FRSO) and the Fonds de Recherche de l'Institut de Cardiologie de Montréal.

1 Weber H, Schmitz L. Catheter technique for closed-chest blation of an accessory atrioventricular pathway. $N$ ablation of an accessory a

2 Morady F, Scheinman MM, Winston SA, DiCarlo LA Jr, Davis JC, Griffin JC, Ruder M, Abbot JA, Eldar M Efficacy and safety of transcatheter ablation of posteroseptal accessory pathways. Circulation 1985;72 $170-7$.

3 Bardy GH, Ivey TD, Coltorti F, Stewart RB, Johnson G, Greene HL. Developments, complications and limitations of catheter-mediated electrical ablation of posterior accessory atrioventricular pathways. $A m \mathcal{F}$ Cardio 1988;61:309-16.

4 Warin JF, Haissaguerre $M$, Lemetayer P, Guillem JP, Blanchot P. Catheter ablation of accessory pathways with a direct approach. Circulation 1988;78:800-15.

5 Haissaguerre M, Warin JF. Closed-chest ablation of left lateral atrioventricular accessory pathways. Eur Heart f $1989 ; 10: 602-10$.

6 Warin JF, Haissaguerre M, D'Ivernois C, Lemetayer P, Montserrat $P$. Catheter ablation of accessory pathways: technique and results in 248 patients. PACE 1990; 13:1609-14.

7 Haissaguerre M, Montserrat P, Warin JF, Donzeau JP, Le Metayer P, Massiere JP. Catheter ablation of left posteroseptal accessory pathways and of long RP' tachycardias with a right endocardial approach. Eur Heart $\mathcal{f}$ 1991;12:845-59.

8 Touboul P, Saoudi N, Atallah G, Kirkorian G, Bouzon R Sun $\mathbf{H}$, de la Bourdonnaye Th. Direct current shock fulguration of accessory AV connections [abstr]. Eur Heart $f 1989 ; 10$ (suppl III-V): 147

9 Linker NJ, Ward DE, Davies MJ, Camm AJ. Fatal coronary sinus rupture following attempted catheter ablation of an accessory pathway. F Electrophysiol 1989;3:2-6.

10 Buxton AE. Catheter ablation of atrioventricular bypass tracts. Still an investigational procedure. Circulation 1989;79:1388-90.

11 Fontaine G, Volmer W, Nienaltowska E, Aaddaj S, Cansell A, Grosgogeat Y. Approach to the physics of fulguration. In: Fontaine $G$, Scheinman $M M$, eds. Ablation in cardiac arrhythmias. New York: Futura Ablation in cardiac arrhych

12 Fontaine G, Cansell A, Lampe L, Baraka M, Tonet JL Frank R, Grosgogeat Y. Endocavitary fulguration (elecrode catheter ablation): equipment-related problems. In: Fontaine G, Scheinman MM, eds. Ablation in cardiac arrhych

13 Ahsan AJ, Cunningham D, Rowland E, Rickards AF. Catheter ablation without fulguration: design and performance of a new system. PACE 1989;12:1157-61.

14 Jordaens L, Roelandt R, Palmer A, Can Wassenhove E, Clement $\mathrm{D}$. Ablation of ventricular tachycardia of right ventricular origin with low energy shocks. $P A C E$ 1989;12:911-6.

15 Jordaens L, Van Wassenhove E, Clement L. Electrocardiographic determinants of efficacy of 8-Joule shocks for ablation of the atrioventricular node. Eur Heart $\mathcal{F}$ 1991;12:608-11.

16 Ayers GM, Wessale JL, Racop CL, Tacker WA, Bourland JD, Geddes LA. Low-energy electrical ablation of A-V junction using a single capacitor discharge [abstr] PACE 1989;12(suppl I):676.

17 Lemery R, Leung TK, Lavallée E, Girard A, Talajic M Roy D, Montpetit M. In vitro and in vivo effects within the coronary sinus of non-arcing shocks using a new system of low energy direct current ablation. Circulation 1991;83:279-93.

18 Lemery R, Lavallée E, Girard A, Montpetit M. Physical and dynamic characteristics of DC ablation in relation to the type of energy delivery and catheter design. PACE 1991;14:1158-68.

19 Huang SK, Bharati S, Graham AR, Lev M, Marcus FI, Odell RC. Closed chest catheter desiccation of the atrioventricular junction using radiofrequency energy: a new method of catheter ablation. $₹ \mathrm{Am}$ Coll Cardiol 1987;9:349-58.

20 Jackman WM, Kuck K-H, Naccarelli GV, Carmen I Pitha J. Radiofrequency current directed across the Pitha J. Radiofrequency current directed across the mitral anulus with a bipolar epicardial-endocardial catheter electrode

21 Jackman WM, Wang X, Friday KJ, Roman CA, Moulton $\mathrm{KP}$, Beckman KJ, McClelland JH, Twidale N, Hazlit HA, Prior MI, Margolis PD, Calame JD, Overhold ED Lazzara R. Catheter ablation of accessory atrioventricular pathways (Wolff-Parkinson-White syndrome) by radiofrequency current. $N$ Engl $f$ Med 1991;324: 1605-11.

22 Calkins $H$, Sousa J, El-Atassi R, Rosenheck S, de Buitleir M, Kou WH, Kadish AH, Langberg JJ, Morady F. Diagnosis and cure of the Wolff-Parkinson-White syndrome or paroxysmal supraventricular tachycardias during a single electrophysiologic test. $N$ Engl $f \mathrm{Med}$ ing a single election.

23 Kuck KH, Schlüter M, Geiger M, Siebels J, Duckeck W. Radiofrequency current catheter ablation of accessory Radiofrequency current catheter ablation of access
atrioventricular pathways. Lancet 1991;337:1557-61.

24 Lemery $R$, Talajic M, Roy D, Coutu B, Lavoie L physiologic outcome of low energy DC ablation in physiologic outcome of low energy DC ablation in patients with the Wolff-Par

25 Leather RA, Leitch JW, Klein GJ, Guiraudon GM, Yee R, Kim YH. Radiofrequency catheter ablation of accessor pathways: A learning experience. Am $\mathcal{F}$ Cardiol 1991;68: 1651-55.

26 Schlüter M, Geiger M, Siebels J, Duckeck W, Kuck K-H Catheter ablation using radiofrequency current to cure symptomatic patients with tachyarrhythmias related to an accessory atrioventricular pathway. Circulation 1991; 84:1644-61.

27 Gallagher J, Pritchett ELC, Sealy WC, Kasell J, Wallace AG. The preexcitation syndromes. Prog Cardiovasc Dis 1978;20:285-322.

28 Kuck KH, Schlüter M. Single-catheter approach to radiofrequency current ablation of left-sided accessory radiofrequency current ablation of left-sided accessory drome. Circulation 1991;84:2366-75.

29 Lemery R, Talajic M, Roy D, Coutu B, Lavoie L, Lavallée E, Cartier $R$. Low energy direct current ablation in patients with the Wolff-Parkinson-White syndrome: Clinical outcome according to accessory pathway location. PACE 1991;14:1951-5.

30 Sealy WC, Gallagher J, Pritchett ELC. The surgica anatomy of Kent bundles based on electrophysiological mapping and surgical exploration. $f$ Thorac Cardiovas Surg 1978;76:804-15.

31 Becker AE, Anderson RH, Durrer D, Wellens HJ. The anatomical substrates of Wolff-Parkinson-White syndrome: a clinicopathological condition seen in patients. Circulation 1978;57:870-9.

32 Becker AE, Anderson R. The Wolff-Parkinson-White syndrome and its abnormal substrates. Anat $\operatorname{Rec} 1981$; 201:169-77.

33 Cox JL, Ferguson TB. Cardiac arrhythmia surgery. In Wells SA, Austen WG, Fonkalsrud EW, Polk HC, Scott HW, Steichen FM, eds. Current problems in surgery. Chicago: Year Book Medical Publishers, 1989:196-278.

34 Connelly DT, Rowland E, Ahsan AJ, Cunningham D. Low energy catheter ablation of a posteroseptal accesLow energy catheter ablation of a posteroseptal accessory pathway associated with a diver
nary sinus. $P A C E$ 1991;14:1217-21.

35 Haissaguerre M, Gaita F, Fischer B, Egloff $P$, Lemetaye $P$, Warin J-F. Radiofrequency catheter ablation of left lateral accessory pathways via the coronary sinus. Circulation 1992;86:1464-8.

36 Scheinman MM. Catheter ablation. Present role and projected impact on health care for patients with cardiac arrhythmias. Circulation 1991;83:1489-98.

37 Seifert MJ, Morady F, Calkins HG, Langberg J. Aortic leaflet perforation during radiofrequency ablation. PACE 1991;14:1582-85.

38 Haines DE, Walker J, Whayne JG, Bruns DE. Creatine kinase is inactivated by radiofrequency catheter ablation and she of myocardial injury [abstr]. Circulation 1991; 84(suppl II):710.

39 Langberg J, Griffin JC, Hene JM, Chin MC, Lev M, Bharati S, Scheinman MM. Catheter ablation of accessory pathways using radiofrequency energy in the canine sory pathways using radiofrequency energy in the
coronary sinus. $\mathcal{F}$ Am Coll Cardiol $1989 ; 13: 491-6$.

40 Morady F, Calkins H, Langbert JJ, Armstrong WF, de Buitleir M, El-Atassi R, Kalbfleisch SJ. A prospective Buitleir M, El-Atassi R, Kalbfleisch SJ. A prospective randomized comparison of direct current and radiofrequency ablation of the atriov 